\title{
Optimization of Transmission Ratios for Two-stage Bevel Helical Gearboxes Based on Mass Function
}

\author{
Tran Thi Hong ${ }^{1}$, Vu Trung Tuyen ${ }^{2}$, Bui Thanh Danh ${ }^{3}$, Tran Thi Phuong Thao ${ }^{4}$, Nguyen Thi Thanh Nga ${ }^{4}$, \\ Tran Ngoc Giang ${ }^{4}$, Nguyen Thanh $\mathrm{Tu}^{4}$ and $\mathrm{Vu}$ Ngoc $\mathrm{Pi}^{4}$,* \\ ${ }^{1}$ Center of Excellence for Automation and Precision Mechanical Engineering, Nguyen Tat Thanh University, Vietnam. \\ ${ }^{2}$ National Research Institute of Mechanical Engineering, Vietnam. \\ ${ }^{3}$ Mechanical Engineering Faculty, University of Transport and Communications, Vietnam. \\ ${ }^{4}$ Mechanical Engineering Faculty, Thai Nguyen University of Technology, Vietnam.
}

\begin{abstract}
:
This study presents a methodology to compute the mass of a two-stage bevel helical gearbox. The objective function depending on the transmission ratios of two stages was examined with the constraint conditions of the important input parameters. These input parameters were given for designing the screening experiment with the help of Minitab 19. The results indicate that not only input parameters but also their interactions have important influences on the optimal transmission ratios. Based on the regression and variance analysis, a mathematical model to compute the optimum transmission ratios was resulted as an explicit equation. The reliability of the mathematical model is verified by the results of the screening experiment. Therefore, the transmission ratios are determined simply. This can increase the economic and technical effectiveness in gearbox design process.
\end{abstract}

Keywords: Bevel Gearboxes, Gear ratio, Gearbox design, Optimization gearbox design.

\section{INTRODUCTION}

In a process of calculating gearboxes, the selection of the partial transmission ratios plays an important role because of its effects on the size, mass, and cost of gearboxes. In regard to methods for determining the partial transmission ratios, the graphical method was investigated in [1-6], which normally uses graphs to calculating gear ratios in a design process. With the practical method, partial transmissions ratios are commonly given in a table by the professional experiences from expert designers [7]. For the model method as found in [8-11], gear ratios are regularly led to mathematical models. For concerning the study on types of gearboxes, the partial transmission ratios have been investigated for two-step gearboxes [5,6,12-16], for three-step gearboxes [17-22], and for four-step gearboxes [4,23].

In recent years, there have been several researches regarding bevel gears. The calculation of gear ratios for three-stage bevel helical gearboxes has been investigated in [19,24]. $\mathrm{Vu}$ and Nguyen [25] proposed the determination partial ratios of a chain drive and gear ratios of a two-step bevel helical gearbox. In this work, both the partial ratio of a chain drive and gear ratios were obtained by minimizing the cross-section function. Besides, examining a two-step bevel helical reducer was also found in [8]. The gear ratios were determined based on the minimum reducer length. However, for two-step bevel helical gearboxes, the optimization problem related to the gearbox mass has not been investigated. Moreover, various factors affecting gear ratios also have not been mentioned in these previous works. Therefore, in this study, we present a methodology to determine transmission ratios based on minimizing the gearbox mass function. Additionally, several input parameters were considered to discuss the effects of them on the optimal transmission ratios. To do this, the screening experiment was conducted with the input parameters. The regression and variance were used to build the explicit equation of the optimum gear ratio.

\section{OPTIMIZATION PROBLEM}

This section presents the procedure to compute the objective function based on the mass of a two-stage bevel helical gearbox. The diagram of a two-stage bevel helical gearbox is described in Figure 1. The main components of this gearbox include the gears, the gearbox housing, and the shafts, which mainly affect the mass of the gearbox. Therefore, the gearbox mass, denoted by $m_{g b}$, can be calculated by

$$
m_{g b}=m_{g}+m_{g h}+m_{s}
$$


Where, $m_{g}, m_{g h}$ and $m_{s}$ are the gear mass, the gearbox housing mass, and the shaft mass, respectively.
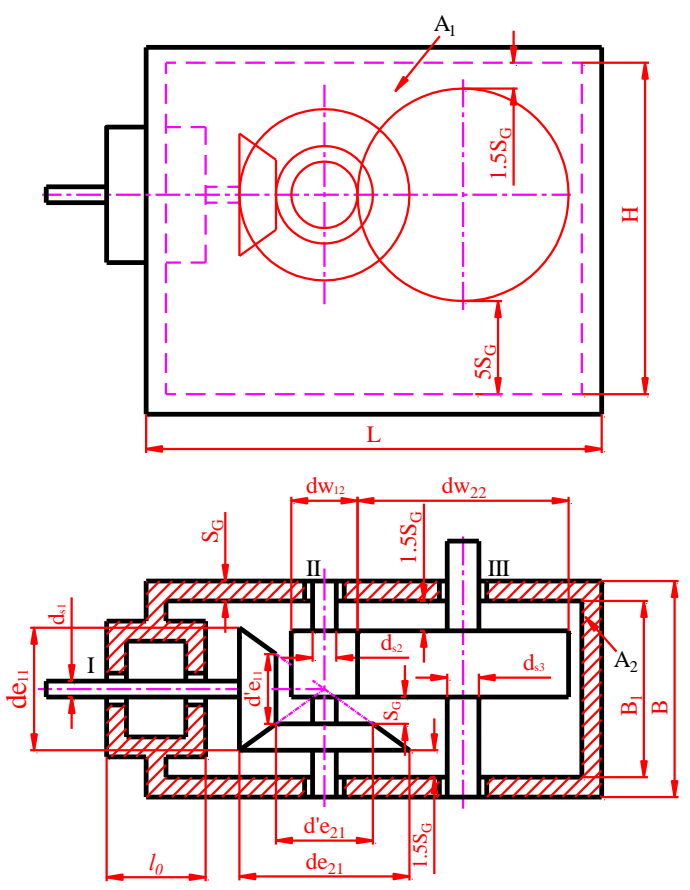

Figure 1. Diagram of calculating gearbox mass for a twostage bevel helical gearbox

\subsection{Gear mass calculation}

As shown in Figure 1, there are two bevel gears of the first stage and two helical gears of the second stage. The total mass of gears is therefore written as

$$
m_{g}=m_{b g 1}+m_{b g 2}+m_{h g 1}+m_{h g 2}
$$

In which, $m_{b g 1}$ and $m_{b g 2}$ are representative for the mass of the pinion and bevel gears $(\mathrm{kg})$, and $m_{h g 1}$ and $m_{h g 2}$ are the mass of the pinion and helical gears $(\mathrm{kg})$, respectively. In general, the mass of each gear can be computed by multiplying the weight density and the volume of gear. Thus, $m_{b g 1}, m_{b g 2}, m_{h g 1}$, and $m_{h g 2}$ can be calculated by:

$$
\begin{gathered}
m_{b g 1}=\rho_{g} \cdot\left\{( \pi / 3 ) \cdot \left[d_{e 11}^{2} \cdot R_{e} \cdot \cos \delta_{1} / 4-d_{e 11}^{\prime 2} \cdot\left(R_{e}-b\right)\right.\right. \\
\left.\left.\cos \delta_{1} / 4\right]\right\} \\
m_{b g 2}=\rho_{g} \cdot\left\{( \pi / 3 ) \cdot \left[d_{e 21}^{2} \cdot R_{e} \cdot \cos \delta_{2} / 4-d_{e 21}^{\prime 2} \cdot\left(R_{e}-b\right)\right.\right. \\
\left.\left.\cos \delta_{2} / 4\right]\right\} \\
m_{h g 1}=\rho_{g} \cdot \pi \cdot e_{1} \cdot d_{w 12}^{2} \cdot b_{w} / 4 \\
m_{h g 2}=\rho_{g} \cdot \pi \cdot e_{2} \cdot d_{w 22}^{2} \cdot b_{w} / 4
\end{gathered}
$$

In Eqs (3) and (4), $\rho_{g}$ is the weight density of gear material $\left(\mathrm{kg} / \mathrm{m}^{3}\right)$; with gear made by steel material, $\rho_{g}=7.82$ [26]; $b$ is the gear width of the bevel gear set $(\mathrm{mm}) ; b=k_{b e} \cdot R_{e}$ (mm) [27]; $R_{e}$ is the cone distance (mm) which can be calculated by [27]:

$$
R_{e}=k_{R} \cdot \sqrt{u_{1}^{2}+1} \cdot \sqrt[3]{T_{11} \cdot k_{h \beta 1} /\left[\left(1-k_{b e}\right) \cdot k_{b e} \cdot u_{1} \cdot\left[\sigma_{H}\right]^{2}\right]}
$$

In here, $k_{R}$ is face width coefficient; for a steel straight bevel gear, $k_{R}=50(\mathrm{MPa})[27] ; k_{H \beta}$ is the contacting load ratio for pitting resistance; for a straight bevel gear set $k_{H \beta}=$ $1.04 \div 1.18$ [27] and choosing $k_{H \beta}=1.11 ; k_{b e}$ is the face width coefficient, $k_{b e}=0.25 \div 0.3$ and choosing $k_{b e}=0.27$; $T_{11}$ is the torque on the pinion; $d_{e 11}$ and $d_{e 21}$ are respectively the outer pitch diameters of the pinion and the gear. With straight bevel gear set, $T_{11}, d_{e 11}$ and $d_{e 21}$ can be computed as [27]:

$$
\begin{aligned}
& T_{11}=T_{\text {out }} /\left(u_{g} \cdot \eta_{b g} \cdot \eta_{h g} \cdot \eta_{b e}^{3}\right) \\
& d_{e 11}=2 \cdot R_{e} /\left(1+u_{1}^{2}\right)^{1 / 2} \\
& d_{e 21}=2 \cdot u_{1} \cdot R_{e} /\left(1+u_{1}^{2}\right)^{1 / 2}
\end{aligned}
$$

In which, $u_{g}$ is the total gearbox ratio; $\eta_{b g}$ is the efficiency of the bevel gear set, $\eta_{h g}=0.95 \div 0.97 \quad$ [27]; $\eta_{h g}$ is the efficiency of helical gear set, $\eta_{h g}=0.96 \div 0.98$ [27]; $\eta_{b e}$ is the efficiency of a rolling bearing pair $\eta_{b e}=0.99 \div 9.995$ [27]. Choosing $\eta_{b g}=0.96 ; \quad \eta_{h g}=0.97, \quad \eta_{b e}=0.992$, $T_{11}$ can be rewritten as:

$$
T_{11}=1.1001 \cdot T_{\text {out }} / u_{g}
$$

In Eqs. (5) and (6), $e_{1}$ and $e_{2}$ are volume coefficients of the pinion and the gear of the helical gear set; $e_{1}=1$ and $e_{2}=$ 0.6 [27]; $b_{w}$ is the gear width of the helical gear set (mm); $b_{w}=X_{b a} \cdot a_{w}$ (mm) [27]; $d_{w 12}$ and $d_{w 22}$ are the pitch diameters of the second step which can be expressed as [27]:

$$
\begin{aligned}
& d_{w 12}=2 \cdot a_{w} /\left(u_{2}+1\right) \\
& d_{w 22}=2 \cdot a_{w} \cdot u_{2} \cdot /\left(u_{2}+1\right)
\end{aligned}
$$

In Eq. (12) and (13), $\boldsymbol{a}_{\boldsymbol{w}}$ is the center distance of the helical gear set which is found by [27]:

$$
a_{w}=k_{a} \cdot\left(u_{2}+1\right) \cdot \sqrt[3]{T_{12} \cdot k_{H \beta} /\left(\left[\sigma_{H 2}\right]^{2} \cdot u_{2} \cdot X_{b a}\right)}
$$

With

$$
T_{12}=T_{\text {out }} /\left(u_{2} \cdot \eta_{h g} \cdot \eta_{b e}^{2}\right)
$$

and $\eta_{h g}=0.97, \eta_{b e}=0.992$ as mentioned above, Eq. (15) can be expressed as:

$$
T_{12}=1.0476 \cdot T_{\text {out }} / u_{2}
$$

In Eq. (14), $k_{H \beta}$ is the contacting load ratio for pitting resistance; for the helical gear set $k_{H \beta}=1.01 \div 1.16$ [27]. It 
can be chosen $k_{H \beta}=1.08 ;\left[\sigma_{H 2}\right]$ is the allowable contact stress of the first stage (MPa); $k_{a}$ is the material coefficient; as the gear material is steel, $k_{a}=43$ [27]; $X_{b a}$ is the coefficient of wheel face width of the helical gear set.

\subsection{Determination of gearbox housing mass}

Using a similar procedure as shown in Sec. 2.1, the gearbox housing mass can be computed as

$$
m_{g h}=\rho_{g h} \cdot V_{g h}
$$

In Eq. (17), $\rho_{g h}$ is the weight density of gearbox housing material, $\rho_{g h}=7,2(\mathrm{~kg} / \mathrm{m} 3)$ with the cast iron material [26]; $V_{g h}$ is the volume of the gearbox housing $\left(\mathrm{m}^{3}\right)$. For determination of $V_{g h}$, the volume gearbox housing can be separated into three parts i.e., $V_{A 1}$ is the volume of font and back sides of the gearbox; $V_{\mathrm{A} 2}$ is the volume of the left and right sides, and $V_{b}$ is the volume of the top and bottom sides. Thus, $V_{g h}$ can be written as

$$
V_{g h}=2 \cdot V_{b}+2 \cdot V_{A 1}+2 \cdot V_{A 2}
$$

In which $V_{b}, V_{A 1}$ and $V_{A 2}$ can be expressed as

$$
\begin{aligned}
& V_{b}=L \cdot B \cdot S_{G} \\
& V_{A 1}=L \cdot H \cdot S_{G} \\
& V_{A 2}=B_{1} \cdot H \cdot S_{G}=\left(B-2 \cdot S_{G}\right) \cdot H \cdot S_{G}
\end{aligned}
$$

In Eqs. (19), (20), and (21), L, H, $B_{1}$ and $S_{G}$ can be determined by:

$$
\begin{aligned}
& H=\max \left(d_{e 21} ; d_{w 22}\right)+6.5 \cdot S_{G} \\
& B=b \cdot \cos \delta_{2}+b_{w}+4 \cdot S_{G} \\
& S_{G}=0.005 \cdot L+4.5
\end{aligned}
$$$$
L=\left(2 \cdot l_{0} / 3+d_{e 21} / 2+d_{w 12} / 2+d_{w 22}+2.5\right) / 0.975[28]
$$

In here, $l_{0}=3 \cdot d_{s 1}$ [27] with $d_{s 1}$ is the diameter of the first shaft which will be determined in the next section; $\delta_{2}$ is the gear pitch cone angle and $\tan \delta_{2}=u_{1}$.

\subsection{Shaft mass calculation}

As shown in Figure 1, the mass of all shafts can be expressed as

$$
m_{s}=m_{s 1}+m_{s 2}+m_{s 3}
$$

In which, $m_{s 1}, m_{s 2}$ and $m_{s 3}$ are respectively the mass of shaft 1,2 and 3 of the gearbox $(\mathrm{kg})$. They can be computed as

$$
\begin{aligned}
& m_{s 1}=\rho_{s} \cdot \pi \cdot d_{s 1}^{2} \cdot l_{s 1} / 4 \\
& m_{s 2}=\rho_{s} \cdot \pi \cdot d_{s 2}^{2} \cdot l_{s 2} / 4
\end{aligned}
$$

$$
m_{s 3}=\rho_{s} \cdot \pi \cdot d_{s 3}^{2} \cdot l_{s 3} / 4
$$

In Eqs. (27), (28), and (29) $\rho_{s}$ is the weight density of shaft material $\left(\mathrm{kg} / \mathrm{m}^{3}\right) ; l_{s 1}, l_{s 2}$ and $l_{s 3}$ are the length of shaft 1,2 and 3 of the gearbox. They can be written as (see Figure 1)

$$
\begin{aligned}
& l_{s 1}=1.3 \cdot l_{0}+1.2 \cdot d_{s 1} \\
& l_{s 2}=B \\
& l_{s 3}=B+1.2 \cdot d_{s 3}
\end{aligned}
$$

In Eqs. (30), (31), and (32), preliminary diameters of the first, second and third shafts i.e., $d_{s 1}, d_{s 2}$, and $d_{s 3}$ are described as [27]:

$$
\begin{aligned}
& d_{s 1}=\left[T_{11} /(0.2 \cdot[\tau])\right]^{1 / 3} \\
& d_{s 2}=\left[T_{12} /(0.2 \cdot[\tau])\right]^{1 / 3} \\
& d_{s 3}=\left[T_{13} /(0.2 \cdot[\tau])\right]^{1 / 3}
\end{aligned}
$$

In which, $[\tau]$ is the allowable shear stress (MPa); $[\tau]=15 \div$ $20(\mathrm{MPa})[27]$ and we can choose $[\tau]=17(\mathrm{Mpa})$.

\subsection{Objective function}

The objective function as shown in Eq. (1) must be minimized

$$
\text { Minimize } m_{g b}
$$

From the above procedure, all calculation parameters of the gearbox mass depend on the transmission ratios of the two stages in the gearbox, i.e., $u_{1}$ and $u_{2}$. Thus, the objective function in Eq. (1) can be expressed as

$$
m_{g b}=m_{g b}\left(u_{1}, u_{2}\right)
$$

Subject to the following constraints:

$$
\begin{aligned}
& 1 \leq u_{1} \leq 9 \\
& 1 \leq u_{2} \leq 9
\end{aligned}
$$

As known that the total ratio of the gearbox, $u_{g}$ as shown in Eqs. (8) and (11)Error! Reference source not found. has the relation with the transmission ratio of the two stages, i.e., $u_{g}=u_{1} \cdot u_{2}$. In general, $u_{g}$ should be used in an interval. Therefore, the objective function in Eq. (37) can be rewritten as

$$
\text { Minimize } m_{g b}=m_{g b}\left(u_{1}\right)
$$

\section{EXPERIMENTAL DESIGN}

The optimum transmission ratio of the first stage $u_{1}$ is obtained by solving Eq. (39) with a computation program. From the relation between the total ratio of the gearbox and gear ratios, the transmission ratio of the second stage is simply determined, i.e., $u_{2}=u_{g} / u_{1}$. Furthermore, a screening 
experiment using Minitab 19 was established to depict the effects of input parameters on the optimum transmission ratio $u_{1}$. As presented in Sec. 2, the input parameters such as the total gearbox ratio $u_{g}$, the coefficient of the face width of the bevel gear set $K_{b e}$, the coefficient of wheel face width of the second stage $X_{b a}$, the allowable contact stress of the first and second stages $A S_{1}$ and $A S_{2}$, and the output torque $T_{\text {out }}$ were taken to design the screening experiment. The value ranges of the input parameters are shown in Table 1. Using 2-level factorial in Minitab with the six parameters, the number of experiments is $2^{6}$ i.e., 64 test runs. The experimental design of the input parameters and the output response values are presented in Table 2 .

Table 1. Input parameters and their level

\begin{tabular}{lllll}
\hline Factor & Code & Unital & Low & High \\
& & & & \\
\hline Total gearbox ratio & $u_{g}$ & - & 7 & 25 \\
Coefficient of the face width of bevel gear set & $K_{b e}$ & - & 0.25 & 0.3 \\
Coefficient of wheel face width of the second stage & $X_{b a}$ & - & 0.3 & 0.4 \\
Allowable contact stress of the first stage & $A S_{1}$ & $\mathrm{MPa}$ & 360 & 420 \\
Allowable contact stress of the second stage & $A S_{2}$ & $\mathrm{MPa}$ & 360 & 420 \\
Output torque & $T_{\text {out }}$ & $\mathrm{Nm}$ & 1000 & 10000 \\
\hline
\end{tabular}

Table 2. Experimental design of input parameters and output response

\begin{tabular}{|c|c|c|c|c|c|c|c|c|c|c|}
\hline StdOrder & RunOrder & CenterPt & Blocks & $\mathbf{u}_{\mathbf{g}}$ & $\mathbf{K}_{\mathbf{b e}}$ & $\mathbf{X}_{\text {ba }}$ & $\mathbf{A S}_{\mathbf{1}}$ & $\mathbf{A S}_{\mathbf{2}}$ & $\mathbf{T}_{\text {out }}$ & $\mathbf{u}_{\mathbf{1}}$ \\
\hline 64 & 1 & 1 & 1 & 25 & 0.3 & 0.4 & 420 & 420 & 10000 & 5.27 \\
\hline 16 & 2 & 1 & 1 & 25 & 0.3 & 0.4 & 420 & 360 & 1000 & 5.74 \\
\hline 52 & 3 & 1 & 1 & 25 & 0.3 & 0.3 & 360 & 420 & 10000 & 5.03 \\
\hline 34 & 4 & 1 & 1 & 25 & 0.25 & 0.3 & 360 & 360 & 10000 & 5.61 \\
\hline 4 & 5 & 1 & 1 & 25 & 0.3 & 0.3 & 360 & 360 & 1000 & 5.51 \\
\hline 44 & 6 & 1 & 1 & 25 & 0.3 & 0.3 & 420 & 360 & 10000 & 5.7 \\
\hline$\ldots$ & & & & & & & & & & \\
\hline 62 & 63 & 1 & 1 & 25 & 0.25 & 0.4 & 420 & 420 & 10000 & 5.46 \\
\hline 35 & 64 & 1 & 1 & 7 & 0.3 & 0.3 & 360 & 360 & 10000 & 1.83 \\
\hline
\end{tabular}

\section{RESULTS AND DISCUSSIONS}

This section presents the results obtained from the screening experiment above. The results are exhibited as the following.

\subsection{The influence of input parameters on the optimum transmission ratio}

Figure 2 shows the effect of each factor on the optimum transmission ratio of the first stage $u_{1}$. It is clearly seen that the relation between the optimal transmission ratio and each factor is described by the straight lines. As observed in Figure 2 , the straight line of $u_{g}$ has the largest slope angle among the input parameters; thus, $u_{g}$ brings the strongest influence on the optimum transmission. The other input parameters have less effects on the output respond compared to the total gearbox ratio.

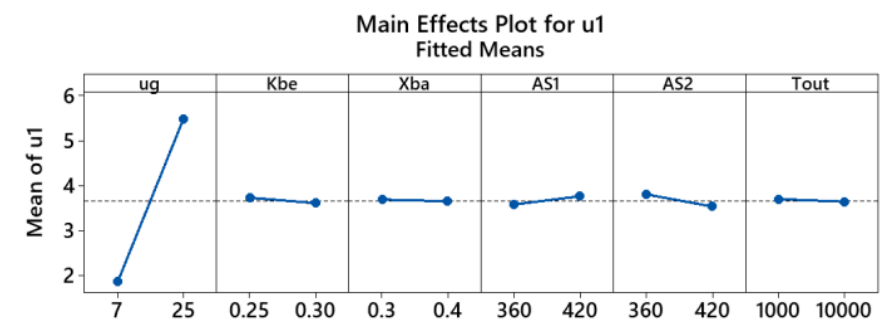

Figure 2. Effects of the factors on the output respond $\mathrm{u}_{1}$ 
In order to evaluate the trend of the effects of the input parameters on the output response, the normal plot of the standardized effects presents the distribution of the input parameters and their interactions as shown in Figure 3. It is observed from Figure 3 that positive effects of the factors and interactions (see the squares in the right side of the reference line) increase the optimum transmission ratio $\mathrm{u}_{1}$ when the settings change from the low value of the factors and interactions to the high value. Otherwise, negative effects located on the left side of the reference line decrease the optimal transmission ratio $\mathrm{u}_{1}$ when they change from the low value to the high value. The effects further from the reference line are more statistically significant e.g., the total gearbox ratio $\mathrm{u}_{\mathrm{g}}$ (factor $\left.\mathrm{A}\right)$.

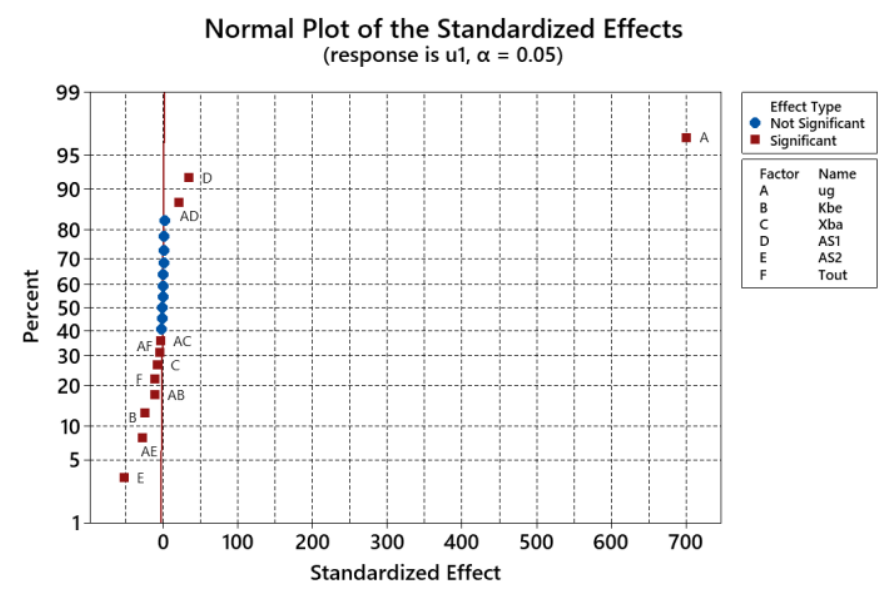

Figure 3. The trend of the effects of factors on the output respond $\mathrm{u}_{1}$

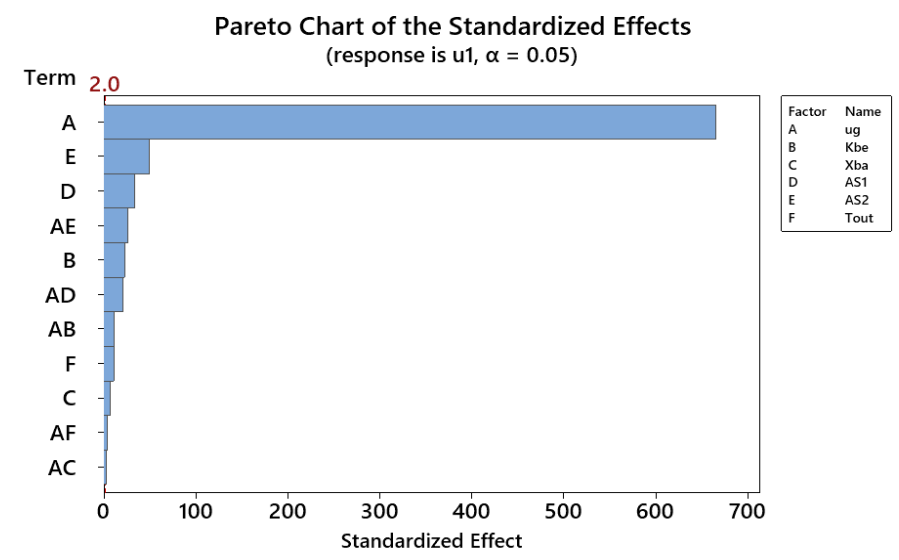

Figure 4. The magnitude of the effects of the factors on the output response $u_{1}$

Figure 4 presents the Pareto chart of the standardized effects with statistical significance at the 0.5 level. In this figure, the influences of the input parameters on the output response are more clearly evaluated by the magnitude of these parameters. As seen in Figure 4, the absolute values of the factors and the interactions are distributed from the lowest to the highest values; therefore, influences of these parameters and interactions are arranged from smallest to largest effects on the optimum transmission ratio $u_{1}$. From the observation in this figure, the total gearbox ratio $u_{g}$ (factor A) has the most important effect on the output response because of its largest magnitude among the factors and interactions.

Besides the influences of the single input factors on the output response, Figure 5 depicts the influences of the interactions of the factors on the optimal transmission ratio. As seen that the interactions including $\mathrm{AB}\left(\mathrm{u}_{\mathrm{g}} * \mathrm{~K}_{\mathrm{be}}\right), \mathrm{AC}\left(\mathrm{u}_{\mathrm{g}} * \mathrm{X}_{\mathrm{ba}}\right), \mathrm{AD}$ $\left(\mathrm{u}_{\mathrm{g}} * A S_{1}\right), \mathrm{AE}\left(\mathrm{u}_{\mathrm{g}} * A S_{2}\right), \mathrm{AF}\left(\mathrm{u}_{\mathrm{g}} * \mathrm{~T}_{\mathrm{out}}\right)$ have significant effects on $u_{1}$.

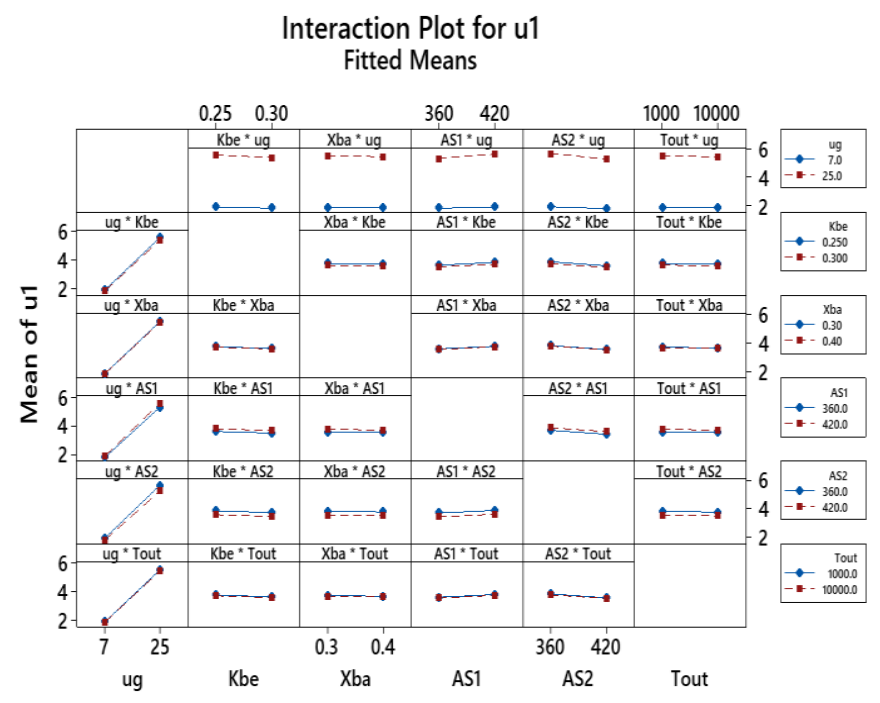

Figure 5. Effects of interactions on the output response $u_{1}$

\subsection{Regression and variance analysis}

After neglecting the insignificant effects on $u_{1}$, the estimated effects and coefficients for the optimum transmission ratio are presented in Table 3. As seen that the input parameters and the interactions have the $p$-values that are smaller than the significant level $(\alpha=0.05)$. Thus, they absolutely have the significant effects on the output response. In addition, the influences of factors and interactions are measured on the second column. The coefficients of those parameters are also shown in the third column. Therefore, the mathematical model can be built by using the analysis regression technique in order to compute the transmission ratio of the gearbox. This model depending on the six input parameters and their interactions can be expressed as

$$
\begin{aligned}
\mathrm{u}_{1}= & 0.780+0.26884 \mathrm{u}_{\mathrm{g}}-0.361 \mathrm{~K}_{\mathrm{be}}-0.086 \mathrm{X}_{\mathrm{ba}}- \\
& 0.000247 \mathrm{AS}_{1}-0.000270 \mathrm{AS}_{2}-0.000002 \mathrm{~T}_{\text {out }} \\
& -0.1306 \mathrm{u}_{\mathrm{g}} * \mathrm{~K}_{\mathrm{be}}-0.01806 \mathrm{u}_{\mathrm{g}} * \mathrm{X}_{\mathrm{ba}} \\
& +0.000205 \mathrm{u}_{\mathrm{g}} * \mathrm{AS}_{1}-0.000265 \mathrm{u}_{\mathrm{g}} * \mathrm{AS}_{2}- \\
& 0.00000001 \mathrm{u}_{\mathrm{g}} * \mathrm{~T}_{\text {out }}
\end{aligned}
$$


International Journal of Engineering Research and Technology. ISSN 0974-3154, Volume 13, Number 7 (2020), pp. 1692-1699

(C) International Research Publication House. https://dx.doi.org/10.37624/IJERT/13.7.2020.1692-1699

To evaluate the reasonability of the mathematic modal as shown in Eq. (40), the correlation coefficient reaches $99,99 \%$ (see Table 3). Due to this the proposed model in Eq. (40) is a good fit to the experimental data. From the model, this can be simple to compute the optimal transmission ratios.

Table 3. Estimated effects and coefficients for $\mathrm{u}_{1}$

\section{Coded Coefficients}

\begin{tabular}{lrrrrrr} 
Term & Effect & Coef & SE Coef & T-Value & P-Value & VIF \\
\hline Constant & & 3.66406 & 0.00273 & 1341.90 & 0.000 & \\
$\mathrm{u}_{\mathrm{g}}$ & 3.63062 & 1.81531 & 0.00273 & 664.83 & 0.000 & 1.00 \\
$\mathrm{~K}_{\mathrm{be}}$ & -0.12250 & -0.06125 & 0.00273 & -22.43 & 0.000 & 1.00 \\
$\mathrm{X}_{\mathrm{ba}}$ & -0.03750 & -0.01875 & 0.00273 & -6.87 & 0.000 & 1.00 \\
$\mathrm{AS}_{1}$ & 0.18188 & 0.09094 & 0.00273 & 33.30 & 0.000 & 1.00 \\
$\mathrm{AS}_{2}$ & -0.27063 & -0.13531 & 0.00273 & -49.56 & 0.000 & 1.00 \\
$\mathrm{~T}_{\text {out }}$ & -0.05875 & -0.02938 & 0.00273 & -10.76 & 0.000 & 1.00 \\
$\mathrm{u}_{\mathrm{q}}{ }{ } \mathrm{K}_{\mathrm{be}}$ & -0.05875 & -0.02938 & 0.00273 & -10.76 & 0.000 & 1.00 \\
$\mathrm{u}_{\mathrm{g}}{ }^{*} \mathrm{X}_{\mathrm{ba}}$ & -0.01625 & -0.00812 & 0.00273 & -2.98 & 0.004 & 1.00 \\
$\mathrm{u}_{\mathrm{q}}{ }^{*} \mathrm{AS} \mathrm{S}_{1}$ & 0.11062 & 0.05531 & 0.00273 & 20.26 & 0.000 & 1.00 \\
$\mathrm{u}_{\mathrm{g}}{ }^{*} \mathrm{~A} S_{2}$ & -0.14312 & -0.07156 & 0.00273 & -26.21 & 0.000 & 1.00 \\
$\mathrm{u}_{\mathrm{q}}{ }^{*} \mathrm{~T}_{\text {out }}$ & -0.02125 & -0.01062 & 0.00273 & -3.89 & 0.000 & 1.00
\end{tabular}

\section{Model Summary}

\begin{tabular}{rrrr} 
S & R-sq & R-sq(adj) & R-sq(pred) \\
\hline 0.0218441 & $99.99 \%$ & $99.99 \%$ & $99.98 \%$
\end{tabular}

Variance analysis was used for more clearly evaluating the significant influences of the input parameters and their interactions on the response. It is observed from the table that all factors and their interactions have important influences on the optimum transmission ratio because their p-values are smaller than the statistically significant value (i.e., $\alpha=0.05$ ). Furthermore, the correlation coefficients are approximate $100 \%$ (see Table 4). Therefore, the variance analysis results are consistent with the regression analysis as shown in Table 3.
Table 4. Variance analysis

\section{Analysis of Variance}

\begin{tabular}{crrrrr} 
Source & DF & Adj SS & Adj MS & F-Value & P-Value \\
\hline Model & 11 & 213.512 & 19.410 & 40678.29 & 0.000 \\
Linear & 6 & 212.922 & 35.487 & 74370.70 & 0.000 \\
$\mathrm{u}_{\mathrm{q}}$ & 1 & 210.903 & 210.903 & 441993.20 & 0.000 \\
$\mathrm{~K}_{\mathrm{be}}$ & 1 & 0.240 & 0.240 & 503.18 & 0.000 \\
$\mathrm{X}_{\mathrm{ba}}$ & 1 & 0.022 & 0.022 & 47.15 & 0.000 \\
$\mathrm{AS}$ & 1 & 0.529 & 0.529 & 1109.17 & 0.000 \\
$\mathrm{AS}_{2}$ & 1 & 1.172 & 1.172 & 2455.78 & 0.000 \\
$\mathrm{~T}_{\text {out }}$ & 1 & 0.055 & 0.055 & 115.74 & 0.000 \\
$2-\mathrm{Way}_{2}$ Interactions & 5 & 0.590 & 0.118 & 247.39 & 0.000 \\
$\mathrm{u}_{\mathrm{q}}{ }^{*} \mathrm{~K}_{\mathrm{be}}$ & 1 & 0.055 & 0.055 & 115.74 & 0.000 \\
$\mathrm{u}_{\mathrm{g}}{ }^{*} \mathrm{X}_{\mathrm{ba}}$ & 1 & 0.004 & 0.004 & 8.85 & 0.004 \\
$\mathrm{u}_{\mathrm{q}}{ }^{*} \mathrm{AS} \mathrm{S}_{1}$ & 1 & 0.196 & 0.196 & 410.35 & 0.000 \\
$\mathrm{u}_{\mathrm{g}}{ }^{*} \mathrm{~A} \mathrm{~S}_{2}$ & 1 & 0.328 & 0.328 & 686.88 & 0.000 \\
$\mathrm{u}_{\mathrm{q}}{ }^{*} \mathrm{~T}_{\text {out }}$ & 1 & 0.007 & 0.007 & 15.14 & 0.000 \\
Error & 52 & 0.025 & 0.000 & & \\
Total & 63 & 213.537 & & & \\
Model Summary & & & & &
\end{tabular}

Model Summary

\begin{tabular}{rrrr} 
S & R-sq & R-sq(adj) & R-sq(pred) \\
\hline 0.0218441 & $99.99 \%$ & $99.99 \%$ & $99.98 \%$
\end{tabular}

The regression model in Eq. (40) was also examined by the normal probability and versus order plots as shown in Figure 6. As seen the normal probability plot (Figure 6.a), the residuals are closely distributed to the standard line (straight line). Additionally, the residuals in the versus order randomly arrange both above and under the standard line (the horizontal axis) (Figure 6.b). Due to these results, the mathematic model is highly reliable to calculate the optimal transmission ratio of the gearbox.

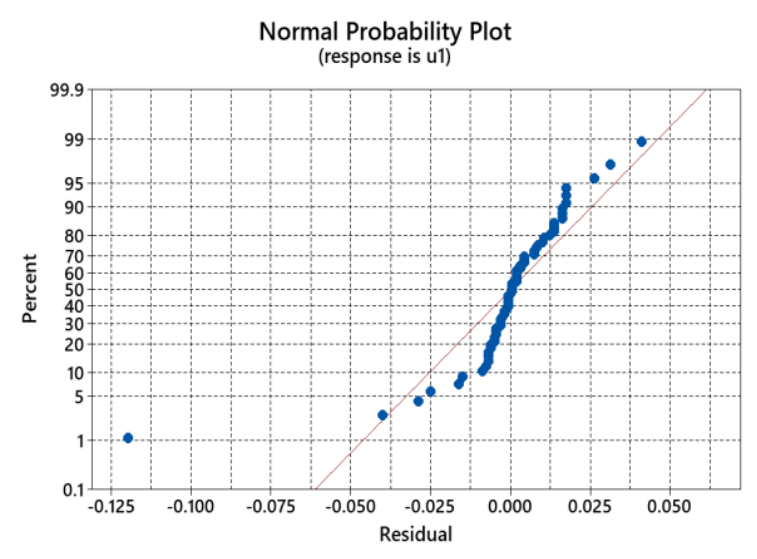

a)

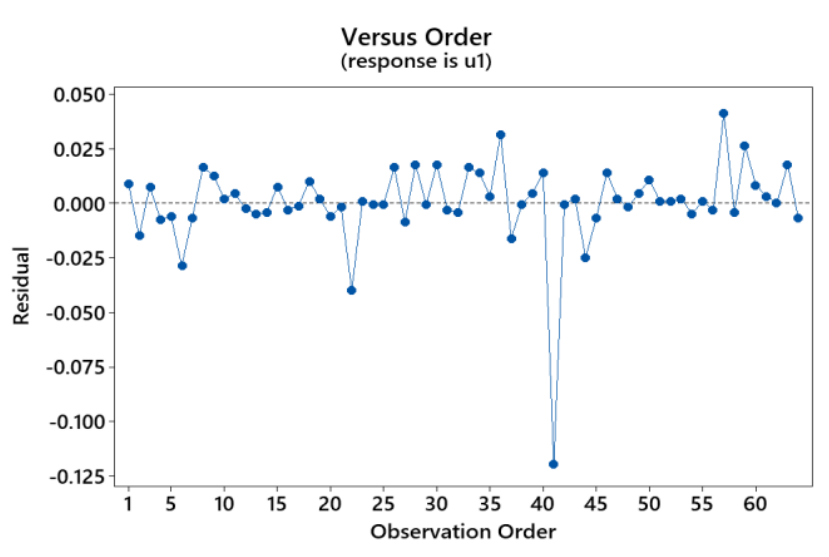

b)

Figure 6. Normal Probability Plot and Versus order plot for the response of $u_{1}$ 


\section{CONCLUSIONS}

In this paper, the mass analysis of a two-stage bevel helical gearbox was proposed in order to determine the optimum transmission ratios based on minimizing the mass function. From the mass analysis, the six input parameters including the total gearbox ratio, the coefficient of the face width of the bevel gear set, the coefficient of wheel face width of the second stage, the allowable contact stress of the first and second stages, and the output torque were investigated. By using Minitab 19 for the experimental design, the influences of the input parameters on the optimum transmission ratio were examined. The results of this study are drawn as the following

- The total gearbox ratio brings the strongest influence on the optimal transmission ratio of the first stage compared to the other input parameters.

- The positive effects of the total gearbox ratio $u_{g}$ and the allowable contact stress of the first stage $A S_{1}$ increase the optimum transmission ratio. Whereas the other parameters i.e., the coefficient of the face width of bevel gear set $K_{b e}$, the coefficient of wheel face width of the second stage $X_{b a}$, the allowable contact stress of the second stage $A S_{2}$, and the output torque $T_{\text {out }}$ have the negative effects to make the decrease of the output response.

- The regression model was carefully evaluated by the correlation coefficients, the p-values, and the normal probability and versus order plots. Therefore, the model can be used to simply compute the optimal transmission ration of the first stage.

Acknowledgements: This work was supported by the Thai Nguyen University of Technology for a scientific project.

\section{References}

[1] V.N. Kudreavtev, I.A. Gierzaves, Design and calculus of gearboxes (in Russian), Mashinostroenie Publishing, Sankt Petersburg, 1971.

[2] A.N. Petrovski, B.A. Sapiro, N.K. Saphonova, About optimal problem for multi-step gearboxes (in Russian), Vestn. Mashinostr. (1987) 13-14.

[3] N. T. Hiep, N. V. Lam, Design of machine elements (in Vietnamese), Educational Republishing House, Hanoi, 1979.

[4] V.N. Pi, Optimal determination of partial transmission ratios for four-step helical gearboxes with first and third step double gear-sets for minimal mass of gears, in: Appl. Comput. Eng., 2008: pp. 53-57.

[5] V.N. Pi, A Study on Optimal Determination of Partial Transmission Ratios of Helical Gearboxes with Second-Step Double Gear-Sets, Int. J. Mech. Mechatronics Eng. 2 (2008) 26-29.

[6] N.P. Vu, A New Study on Optimal Calculation of Partial Transmission Ratios of Helical Gearboxes with First-step Double Gear-sets, in: Lect. Notes Eng. Comput. Sci., 2008: pp. 162-165.

[7] G. Milou, G. Dobre, F. Visa, H. Vitila, Optimal Design of Two Step Gear Units, regarding the Main Parameters, VDI Berichte. 1230 (1996) 227-244.

[8] T.H. Tran, N. V. Cuong, L.H. Ky, N.K. Tuan, N.P. $\mathrm{Vu}$, Calculating Optimum Gear Ratios of Two Step Bevel Helical Reducer, 14 (2019) 3494-3499.

[9] N.T.H. Cam, N.P. Vu, T.T. Hong, L.. H. Ky, L.A. Tung, A study on calculation of optimum gear ratios of a two-stage helical gearbox with second stage double gear sets, Int. J. Mech. Prod. Eng. Res. Dev. 9 (2018) 613-620.

[10] N.K. Tuan, N.P. Vu, N.T.H. Cam, T.T.P. Thao, H.K. Thanh, L.X. Hung, H.T. Tham, Determining Optimal Gear Ratios of a Two-stage Helical Reducer for Getting Minimal Acreage of Cross Section, in: Asia Conf. Mech. Mater. Eng., 2018: pp. 1-5.

[11] N.K. Tuan, T.T. Hong, N. V. Cuong, L.H. Ky, N.T. Tu, L.A. Tung, L.X. Hung, N.P. Vu, A Study on Determining Optimum Gear Ratios of Mechanical Driven Systems Using Two-Step Helical Gearbox with First Step Double Gear Sets and Chain Drive, in: Adv. Eng. Res. Appl., 2020: pp. 85-93.

[12] N.P. Vu, N.K. Tuan, L.X. Hung, L.A. Tung, A New Study on Determination of Optimum Gear Ratios of a Two-Stage Helical Gearbox, in: Adv. Mater. Sci. Eng., 2020: pp. 107-115.

[13] N.T.H. Cam, N.P. Vu, N.K. Tuan, L.X. Hung, T.T.P. Thao, Determining Optimal Partial Transmission Ratios of Mechanical Driven Systems Using a V-Belt Drive and a Helical Reducer with Second-Step Double Gear-Sets, in: Int. Conf. Eng. Res. Appl., 2019: pp. 261-269.

[14] N.K. Tuan, V.P. Pi, Optimum Calculation of Partial Transmission Ratios of Mechanically Driven Systems Using a V-Belt and a Helical Gearbox with First-Step Double Gear Sets, Int. J. Mech. Eng. Robot. Res. 8 (2019) 323-326. 
[15] A.T. Luu, T.T. Hong, N. V. Cuong, L.H. Ky, N.T. Tu, L.X. Hung, N.P. Vu, A Study on Determination of Optimum Gear Ratios of a Two-Stage Worm Gearbox, in: Adv. Eng. Res. Appl., 2020: pp. 76-84.

[16] T.H. Tran, N. V. Cuong, L.H. Ky, N.T. Tu, V.N. Pi, Calculating Optimum Gear Ratios of Mechanical Driven Systems Using Worm-Helical Gearbox and Chain Drive, Int. J. Appl. Eng. Res. 14 (2019) 32113218.

[17] N.T.H. Cam, N.P. Vu, N.K. Tuan, L.X. Hung, T.P.T. Tran, Determining Optimum Partial Transmission Ratios of Mechanical Driven Systems Using a V-Belt Drive and a Three-Stage Helical Reducer, in: Adv. Eng. Res. Appl., 2019: pp. 81-88.

[18] N.K. Tuan, T.P.T. Tran, N.T.H. Cam, L.X. Hung, N.P. Vu, Optimum Calculation of Partial Transmission Ratios of Mechanical Driven Systems Using a V-Belt and a Three-Step Bevel Helical Gearbox, in: Adv. Eng. Res. Appl., 2019: pp. 469476.

[19] N.P. Vu, T.T.P. Thao, T.T. Hong, N.K. Tuan, L.X. Hung, L.A. Tung, Determination of optimum gear ratios of a three stage bevel helical gearbox, in: Mater. Sci. Eng., 2019: pp. 1-8.

[20] N.P. Vu, K.T. Nguyen, X.H. Le, T.H.C. Nguyen, T.P.T. Ttan, Determining Optimum Partial Transmission Ratios of Mechanical Driven Systems Using a V-Belt Drive and a Three-Stage Helical Reducer, in: Adv. Mater. Sci. Eng., 2020: pp. 1-6.

[21] N.P. Vu, A new study on the optimal prediction of partial transmission ratios of three-step helical gearboxes with second-step double gear-sets, Appl. Theory Mech. 2 (2007) 229-238.

[22] O. Buiga, 3 Stage helical speed reducer partial gear ratios optimal determination using genetic algorithms, Proc. Rom. Acad. Ser. A - Math. Phys. Tech. Sci. Inf. Sci. 20 (2019) 156-163.

[23] N.P. Vu, Optimal calculation of partial transmission ratios for four-step helical gearboxes with first and third step double gear-sets for minimal gearbox length, in: Proc. Am. Conf. Appl. Math., 2008: pp. 29-32.

[24] T.T.P. Thao, T.T. Hong, N. V. Cuong, L.H. Ky, N.T. Tu, L.X. Hung, P. V. Ngoc, Determining Optimum Gear Ratios of Mechanical Driven Systems Using Three Stage Bevel Helical Gearbox and Chain Drive, in: Adv. Eng. Res. Appl., 2020: pp. 249-261.

[25] V.N. Pi, N.K. Tuan, Determining optimum partial transmission ratios of mechanical driven systems using a chain drive and a two-step bevel helical gearbox, Int. J. Mech. Eng. Robot. Res. 8 (2019) 708712 .

[26] T.E. Toolbox, Density, Specific Weight and Specific Gravity, (n.d.).

[27] T. Chat, L. V. Uyen, Calculation of mechanical driven systems (in Vietnamese), Education Publisher, 1996.

[28] I. RÖMHILD, H. Linke, Gezielte Auslegung Von Zahnradgetrieben mit minimaler Masse auf der Basis neuer Berechnungsverfahren. Konstruktion, Konstruktion. 44 (1992) 229- 